\title{
RENTA BÁSICA, DERECHOS Y PLANIFICACIÓN ECONÓMICA. ESBOZO PARA UNA DISCUSIÓN REPUBLICANA
}

\section{BASIC INCOME, RIGHTS AND ECONOMIC PLANNING. OUTLINE FOR A REPUBLICAN DISCUSSION}

\section{Jesús Rodríguez Rojo}

Investigador independiente, Sevilla, España

jesusrrojo@gmail.com

Palabras clave: Renta básica; planificación económica; republicanismo; derechos sociales.

Keywords: Basic income; economic planning; republicanism; social rights.

Resumen: en el presente documento se tratará de contraponer dos medidas que pretenden ser la materialización de la tradición republicana: la renta básica universal y la planificación económica democrática. Aunque ambas responden a premisas significativamente diferentes, pueden ser evaluadas desde los mismos parámetros, aquellos cuya base ya instauró la llustración. Se compararán de acuerdo a su capacidad de respuesta ante el desafío que supone el pretender convertir en derechos las demandas ciudadanas, empezando por la reproducción social.

Abstract: this document will try to contrast two measures that claim to be the materialization of the republican tradition: universal basic income and democratic economic planning. Although both respond to significantly different premises, they can be evaluated from the same parameters, those whose base has already been established by the Enlightenment. They will be compared according to their capacity to respond to the challenge of trying to convert citizen demands into rights, starting with social reproduction.

\section{l, lntroducción}

La Renta Básica Universal (RBU) es uno de esos temas de debate recurrentes. Que encuentra picos de interés por parte de ciertos grupos de población, y tan rápido llega a la palestra pública y, por tanto, a los titulares, como se marcha para dar paso a otros asuntos de la actualidad política. Si bien esto puede leerse como la incapacidad de sus promotores para consolidar su relevancia en la agenda pública, no es menos cierto que algo debe tener la propuesta (y sus partidarios) para que al menos cada vez que la eco- 
nomía sufre un revés regrese al candelero. Es por eso que resulta de gran interés para las ciencias sociales la discusión sobre si todo el mundo debe recibir, por el simple hecho de ser ciudadano, una asignación monetaria periódica por parte de las administraciones públicas. Ese será el objetivo del presente documento: profundizar en la ya amplia gama de discusiones en torno a la RBU. En concreto, lo haremos contraponiendo esta propuesta con otra que responde a un proyecto político netamente distinto y, diríamos, contrapuesto, la planificación económica. En resumidas cuentas, lo que pretendemos no es otra cosa que aproximarnos de manera muy sintética, como una modesta incursión dialéctica, a los aspectos que diferencian ambas formas de dar respuesta, a través de derechos materialmente respaldados, a demandas ciudadanas.

A tales efectos no nos preocuparemos por profundizar en los aspectos más, digamos, concretos de la RBU ni de la planificación. No entraremos a hacer números ni a valorar su viabilidad o idoneidad para un contexto particular. Concederemos todo el protagonismo a los argumentos. En este sentido empecemos por dar una breve explicación de lo que es la RBU como la abordaremos en el resto del documento.

\section{Las características de la RBU: argumentos y contraargumentos en su defensa}

Aunque el debate sobre la renta básica tal y como la entendemos se remonta a finales del siglo pasado, hoy este proyecto goza de una salud encomiable; buena cuenta de ello da la cantidad de libros que, en el contexto español reciente, abordan qué es y qué consecuencias puede acarrear su implantación. La mayoría de ellos de forma apologética (Arcarons et al., 2017; Raventós, 2001, 2012), pero otros de forma más bien crítica, desde un liberalismo más o menos radical (Rallo, 2015), pero también desde posiciones más izquierdistas (Torres, 2019). Ante tal abanico, nos vemos obligados a tomar alguno como referencia, que, siendo representativo de lo que genéricamente se entiende por renta básica, nos sirva de guía para tratar de poner en orden los diferentes argumentos. En este sentido nos hemos decantado, siguiendo estos criterios, por seleccionar el libro Por una renta básica universal del profesor R. Soriano (2012). En él leemos algo que es particularmente cierto para la RBU, que - en aras de distinguirla de otras rentas que pudieran asemejarsela «mejor definición [...] es la exposición de sus características o notas distintivas»; abreviadamente, estas serían: se asigna de forma individual, incondicional, universal, uniforme, permanente, básica, inmediata, periódica, en metálico, por parte preferentemente del Estado y de forma compatible y complementaria con otro tipo de ayudas o subsidios (Soriano, 2012, pp. 19-23).

¿Qué conseguiría la población con la instauración de la renta básica? Esa es la pregunta clave, y por tanto es aquí donde sus partidarios descargan toda su artillería. A fin de cuentas, lo que vienen a decir puede resumirse con los siguientes argumentos. Gracias a su instalación se lograría, antes de nada, potenciar la igualdad de oportunidades. Los ciudadanos tendrían un suelo de ingresos superior al umbral de la pobreza, uno que les evitaría el estigma que surge de otro tipo de asignaciones públicas. Al ser incondicional, ya no habría incentivos para tratar de engañar a las instituciones 
con tal de no perder una fuente de ingresos; por el contrario, haría que proliferaran los empleos a tiempo parcial de tal manera que el desempleo se resienta duramente. Serviría también para otorgar un reconocimiento en forma monetaria al trabajo impagado de las mujeres en el hogar a la par que refuerza los lazos intergeneracionales gracias a la distribución de los frutos del trabajo social. Todo esto, además, tendría, como ya se ha dicho, un carácter permanente, con lo que quedaría fuera de los juegos político-partidistas (Soriano, 2012, pp. 37-48)... Pero aún hay más.

Estas serían las virtudes de la RBU como derecho, pero esta no sería «solamente un derecho, sino un derecho-presupuesto del ejercicio y eficacia de los demás derechos» (Soriano, 2012, p. 39). Una vez que la persona tiene satisfechas sus necesidades básicas se hará efectiva la "capacidad de elegir entre una gama de ofertas de actividades y trabajo, y la capacidad de decidir voluntariamente y no por presiones externas el destino que cada persona quiere dar a su vida» (Soriano, 2012, p. 44). Los trabajadores, más allá de tener una mejor capacidad de negociación, ganarían el poder de realizar sus aspiraciones vitales gracias a la tranquilidad de tener un ingreso garantizado. Con su correcta implementación se lograría ni más ni menos que la «materialización y culminación de las aspiraciones del Estado social»: «la pobreza se extinguirá y el Estado social cumplirá su fin último que es la garantía de unas condiciones dignas de vida para todos los ciudadanos» (Soriano, 2012, p. 47). La RBU significaría, dicho de otra forma, «la formula de cierre del ascendente reconocimiento de la segunda generación de los derechos humanos, los derechos sociales» (Soriano, 2012, p. 30). En definitiva, sus defenso- res se enfrentan a esta medida como la plena realización de los principios republicanos de igualdad, libertad y fraternidad, como también de la democracia.

Desde que se popularizó la idea de la RBU surgieron todo tipo de críticas; críticas que, por supuesto, hallaron réplica desde los impenitentes valedores de la propuesta. Cuando se argüía que su puesta en práctica rompería el principio de reciprocidad respondieron que tal principio estaba roto desde la base en una sociedad como la actual, en la que hay quienes nacen condenados a la miseria y otros con la vida resuelta. Ante las dudas sobre su viabilidad espetaron varios modelos alternativos de financiaciones factibles. ¿Quitaría protagonismo al trabajo en nuestra sociedad? ¡En absoluto!, contestaron, la RBU no interfiere en la inmensa mayoría de los incentivos que llevan al ser humano a trabajar y que van mucho más allá de conseguir un sustento. Y por supuesto, no existiría un riesgo real de crisis, a los empresarios se les resarciría del daño que reciban en forma de impuestos o potenciación de la negociación colectiva mediante el aumento del consumo (Soriano, 2012, pp. 48-55). El hecho de que no hubiese golpe - viniera por derecha o por izquierda- que no tratase de encajar y devolver mediante el desarrollo teórico los impulsores de la renta básica seguramente sea una de las razones por las que han ido consiguiendo mantener su propuesta en buena forma desde hace años.

\section{Hacia una crítica materialista y republicana de la renta básica}

Hemos ya indicado que los abanderados de la RBU contemplan su proyecto, sin 
escatimar en retórica, como la flor y nata de la llustración. Según sostiene Raventós (2011) en un interesante artículo, la renta básica podría considerarse justa desde el punto de vista liberal pero también, y sobre todo, desde el republicano. Estos dos grandes prismas que vertebraron el pensamiento del siglo de las luces vendrían unidos, al menos en las vertientes que les interesa poner en valor, a alumbrar la necesidad de otorgar a cada persona una cierta cantidad de dinero para que se desenvuelva con dignidad en la sociedad. Aunque sin duda el asunto es complejo por la cantidad de aristas que lo recorren de principio a fin, consideramos que el conflicto que aspiramos a esbozar en estas páginas, aquel que enfrenta la RBU con la planificación económica, puede contemplarse como si de una contradicción en el seno de la llustración se tratase. Ambas propuestas responden de diferentes maneras al gran reto que se planteó con la fundación de los estados burgueses: cómo los ciudadanos deben otorgarse derechos para desarrollar sus aspiraciones en libertad. A continuación trataremos de ver cómo desde la renta básica se recoge el legado republicano en una vertiente muy concreta: la liberal.

\section{I Preludio a la crítica: del hándicap de la falta de una base material a las fallas potenciales}

Seguramente uno de los problemas más importantes de la RBU surge debido al plano en que se desarrolla la discusión. Aunque como adelantamos no vamos a profundizar en los aspectos técnicos de la renta básica, resulta esclarecedor que, antes de sumergirnos en el núcleo de la crítica, nos preocupemos por dejar en claro algunos puntos destacables. En particular, hay que destacar la dificultad que entraña el mostrarnos incapaces de encontrar una base material sobre la que asentar la discusión, un lugar donde la aplicación de la RBU se haya ajustado a la teoría propugnada. El mismo Soriano (2012, pp. 119-129) ofrece una rigurosa revisión de las diferentes tentativas que, cuando escribió su libro, se habían desarrollado - Alaska, Brasil, Argentina, México, País Vasco...-. Esa lista podría ser actualizada -incluyendo, por ejemplo, Finlandia, Irán, Kenia o Canadá-, y aún con ello nos es imposible dar con un solo caso en que se trate de un ingreso con las características antedichas sostenido en el tiempo, que se incluya de forma firme en los ordenamientos. En la mayoría de casos se trata, o bien de «experimentos» acotados a cierta población y en cierto margen temporal, o bien de rentas con condicionantes como la edad o la «situación de exclusión social». Todo indica que existen trabas serias para su implementación, algunas de las cuales conviene recordar.

Supongamos, en el marco hipotético en el que se sitúa la discusión, que efectivamente se aplica la renta básica. Todos los ciudadanos, al visitar nuestra página del banco a final de mes encontraríamos una cantidad $X$ de dinero extraída por medio de impuestos a la población más rica. Lo que ocurriría rápidamente sería una caída generalizada de los salarios, puesto que una parte del valor de la fuerza de trabajo ya se está abonando en concepto de renta (para un somero recorrido por las determinaciones del valor de la fuerza de trabajo véase: Rodríguez Rojo, 2019; y para un desarrollo más profundo: Caligaris y Starosta, 2017, cap. 4). Esto se podría expresar inmediatamente o por medio del recorte de otras formas de «salario indi- 
recto» como los servicios públicos: ¿acaso no es eso lo que reclaman ciertos economistas «neoliberales» cuando reclaman la renta básica? También, por supuesto, hay grandes probabilidades de que el movimiento se saldase con un aumento generalizado de los precios, al menos en muchos productos y en las primeras etapas de su implementación': los arrendadores serían conscientes de que todos los posibles inquilinos gozan de más dinero para abonar mensualmente a la vez que tendrían un ingreso más que les quitaría gran parte de la presión de sacar rentabilidad a sus activos inmobiliarios.

Ante esta posibilidad, sus defensores se refugian siempre en que la RBU debería aplicarse en combinación con otras medidas legales que contendrían sus efectos más perjudiciales. Tal como llegan a plantearlo, los mercados serían una «creación de la ley» (Raventós, Torrens y Arcarons, 2014). En este argumento es ciertamente discutible e incluso, nos atreveríamos a decir, algo iluso. El modo de producción capitalista funciona a partir de leyes objetivas, que rigen al margen de la voluntad de los agentes (como las que, siguiendo a Marx, registran obras actuales de la magnitud de: Arrizabalo, 2014; Nieto, 2015; Shaikh, 2016). Es por esa razón que el metabolismo social no puede moldearse al arbitrio de los legisladores. Tratar de evitar este tipo de dinámicas a expensas de la rentabilidad del capital sin realizar cambios más profundos no podría reflejarse más que en la devastación econó-

\footnotetext{
1. Podríamos aceptar -siempre en este supuesto marcado por la abstracción- que una vez implantada la renta básica, si esta es modulada de acuerdo a ciertos indicadores como la productividad (como sugieren Peña-Miguel y Peña Esteban, 2014, p. 26), no tendría por qué darse de forma sostenida.
}

mica. Por esa misma razón, prohibir el despido no acabaría con el desempleo, ni tratar de elevar abruptamente el salario mínimo se plasmaría directamente en el alza generalizada de los mismos. Si se llegase al punto de vernos cerca de tal escenario resultaría en vano todo intento de recordar que entre las características de la RBU figuraba el hecho de que se tratase de una reforma permanente: súbitamente se derogarían los decretos necesarios para reconducir la situación y remontar la tasa de ganancia. Pero dejemos de lado esto para concentrarnos en el que desde el principio es el objeto del artículo, atendamos a la forma en que los impulsores de esta medida la justifican desde los valores republicanos.

\subsection{La libertad que da la renta básica es la libertad que otorga el dinero}

Seguramente el aspecto más crítico de la discusión que abordamos sea el carácter monetario de la asignación. En relación a él se sitúa el grueso de la confrontación. El problema nuclear gira en torno a si es el otorgar cierta cantidad de dinero de manera periódica aquello llamado a conseguir potenciar la libertad de los individuos. A fin de cuentas, lo que la RBU perseguiría es erigirse como un "poderoso instrumento» en la promoción de la «libertad real para todos» (Van Parijs, 2001, p. 3). Lógicamente, existen poderosas razones para pensar que sí, al fin y al cabo, el dinero es hoy, gracias a su condición de privilegiada entre las mercancías, la mediación por excelencia entre la voluntad y su realización; como diría poéticamente el propio Marx (1999, p. 177), siguiendo a Shakespeare, «es el alcahuete entre la 
necesidad y el objeto». Lo que recibirían los ciudadanos sería nada menos que poder abstracto sobre el producto del metabolismo social. En román paladino, el dinero da libertad porque gastándolo puedes conseguir, a priori, lo que te plazca. Si se desea, como reza uno de los grandes ejemplos canónicos, dedicar la vida a surfear viviendo de forma austera, con una cierta cantidad de euros al mes podría hacerlo, uno sería «libre» de hacerlo.

En aras de encontrar puntos de confluencia entre el liberalismo y el republicanismo en torno a la RBU, Raventós (2011, pp. 225, 232) cita en el mismo texto hasta en dos ocasiones el mismo fragmento de un texto de Van Parijs sobre, por así decir, el mínimo común de las teorías liberales de la justicia; este sería «una concepción que prohíbe toda jerarquía de las diversas concepciones de la vida buena que puedan encontrarse en la sociedad». En definitiva, para el liberalismo no podría ser justo que alguien impusiera sobre otra persona su propia forma de ser feliz; cada uno puede tener su forma de realizarse y - mientras no coarte la libertad ajenadebe tener derecho a alcanzarla. La renta básica permitiría esto. De hecho, cuando Soriano (2012, p. 22) argumenta en favor del carácter metálico de la renta frente al pago «en especie» destaca en primer lugar que «permite que el beneficiario haga uso de la misma con mayor libertad y posibilidades»; a lo cual acto seguido añade que lo hace evitando «la dificultad de los criterios de opinión sobre qué bienes en concreto deben definirse como bienes que conectan con las necesidades básicas». En definitiva, la dotación monetaria evita tener que acordar o consensuar necesidades comunes adecuándose a las demandas que los individuos, de forma desagregada, estimen oportunas.
Voluntariamente o no, se encierra a los valores republicanos en el estrecho marco que establece el pensamiento liberal. La soberanía recae directamente sobre el individuo aislado dotado de recursos, no sobre el colectivo organizado. Seremos libres sobre el seguro sostén del dinero que necesitemos para no morir de inanición:

La independencia, la existencia material, la base autónoma (son expresiones aquí perfectamente permutables) que confiere la propiedad es condición indispensable para el ejercicio de la libertad. De ahí la idea sugerida por parte de los defensores republicanos de la Renta Básica: «universalizar la propiedad». Universalizar la propiedad debe entenderse de forma metafórica. Nadie está pensando seriamente en repartir la propiedad de un país dado, o del mundo, entre los habitantes del país en cuestión, en el primer caso, o del mundo entero, en el segundo. Universalizar la propiedad debe ser entendido aquí de forma equivalente a garantizar a todos la existencia material (Raventós, 2011, p. 233).

Aunque no nos resulte de agrado reconocerlo, nadie como el jurista nazi Schmitt (2014, p. 100) supo ver tras la desconfianza ante el Estado y la política del liberalismo «los principios de un sistema para el cual el individuo es y debe seguir siendo tanto terminus a quo como terminus ad quem». Tras la erudición de nuestros autores atisbamos un sistema idéntico. En este sentido hay algo de razón tras las acusaciones vertidas contra la RBU que señalan que su reivindicación supone una capitulación ante el avance del «neoliberalismo» (Zamora, 2017). Pese a lo desacertado del sustantivo en cuestión -que en ocasiones se emplea de forma en extremo vaga-, sí pareciera que el horizonte de las luchas sociales estaría dado en el plano puramente circulatorio-mercantil. Las 
aspiraciones quedan restringidas al plano de la capacidad de consumo. No nos parece demasiado atrevido tratar de llevar algo más allá los objetivos inmediatos de la acción política emancipadora (tanto en el medio como incluso en el corto plazo) soltando amarras respecto a la tradición liberal. Para ello sugerimos que un buen punto de partida sería preguntarnos: iy si no entendiésemos eso de «universalizar la propiedad» de forma «metafórica» sino literalmente? Ese es el ejercicio mental que podría llevarnos a la que vamos a contemplar y analizar como la alternativa aquélla que venimos avanzando: la planificación económica mediada por mecanismos de participación democráticos.

\section{La planificación democrática, otro nexo de unión entre la tradición republicana y socialista}

Estamos dispuestos a aceptar de buena gana que, como ha sugerido con perspicacia Doménech $(2013,2019)$, existe un poderoso nexo de unión entre las tradiciones republicana y socialista. Esto lo comparten también nuestros interlocutores, para los que el entrelazamiento entre el programa de Marx y de Sièyes tomaría cuerpo en el carácter universal de la renta básica (Raventós y Casassas, 2003). Sin embargo, para llegar a ello necesitan pasar por una, en nuestra opinión, grosera tergiversación del proyecto político socialista clásico; de lo contrario resultaría poco menos que imposible conciliarlo a la vez con el paradigma liberal. Ya han sido muchos los que han puesto de relieve la radical incompatibilidad entre el relato que subyace a los planteamientos de la renta básica — la distribución de los recursosy el que vertebra las posiciones socialistas - la forma de organizar la producción social-, por tanto no consideramos necesario abundar en ello (Albarracín, 2015; Astarita, 2018, p. 256; Del Rosal, 2019, p. 226; Husson, 2017). Lo que trataremos de demostrar es por qué el establecimiento de una forma de planificación democrática de la economía tiene la potencialidad de consumar la aspiración emancipadora que dio comienzo con la revolución francesa y que se concreta en la consolidación de derechos para toda la población.

Uno de los elementos que caracteriza el mundo moderno es la separación que se establece entre la esfera pública o política, en la que somos ciudadanos, y la privada, en la que únicamente somos individuos (cf. Capella, 1997, pp. 110-111). Ya entonces se estableció una suerte de muro infranqueable entre lo concerniente al Estado, donde las decisiones deben ser fiscalizadas por el «pueblo soberano", y aquello que atañe al mercado, terreno reservado a los designios de cada productor y consumidor. El capital, fragmentado en diferentes entidades productivas independientes, solo puede mostrar su unidad a través de una expresión "política» enajenada de su contenido «económico». No obstante, estas instancias de la sociedad no son una realidad inamovible: llegado cierto punto, se mantiene una pugna en la que una no puede avanzar si no es sobre la otra.

La implementación de un modelo de planificación tras la toma del poder por parte de la clase obrera no sería - tal y como lo entendemos - otra cosa que la forma en que se impone la esfera política sobre el conjunto de la producción social. El proletariado convierte en una realidad mate- 
rial las dimensiones del proyecto ilustrado que la burguesía no pudo más que imaginar, presa su praxis de los medios que posee 0 , tal vez mejor dicho, por los que es poseída. Traspasando los límites del pensamiento burgués (y suprimiendo la clase capitalista como clase social) la condición de ciudadanía se fortalece al otorgar un carácter netamente político a la gestión del metabolismo social en su totalidad. La propiedad del capital se universaliza como propiedad pública, propiedad del Estado. Las necesidades básicas y, por qué no, todas las demás, se ven satisfechas sin que intervenga la competencia, a través de una única entidad sometida a pautas democráticas que sería responsable de la producción global de mercancías. Los ciudadanos se hacen partícipes colectivamente de los procesos que involucra su reproducción. Tal sería la desembocadura del tortuoso cauce que han seguido las luchas por los Derechos Humanos (véase, Rodríguez Rojo, 2020a). Las conquistas obreras en la sociedad burguesa se consuman con la abolición de esta última como producto lógico del despliegue del «Estado del bienestar».

Hemos visto que los defensores de la RBU blindan su propuesta por medio de dos argumentos. Uno es de carácter técnico y lo expresan en términos similares a los liberales más radicales (Hayek, 1997): sería muy imposible reunir y analizar las preferencias individuales con vistas a planificar la economía. No nos detendremos en este punto. Creemos que en trabajos recientes ya se ha aportado evidencia suficiente de que, gracias a la capacidad de recolección y procesamiento de información que ofrecen los avances técnicos, hoy es posible prescindir de la caótica concurrencia para atender a las necesidades de la sociedad (véase en este sentido:
Nieto, 2020; Cockshott y Nieto, 2017). Más nos interesa el otro argumento, aquel que se refiere a que, disponiendo del dinero en metálico los individuos serán más libres de adquirir aquello que a cada uno le satisfaga. Este es el resultado de la influencia de los vestigios liberales que siguen ocupando una posición destacada a la hora de articular sus planteamientos.

Lo que la planificación ofrece no es, en realidad, una alternativa al uso de las mercancías en general, ni del dinero en particular. Toda la experiencia y análisis apuntan a que las mercancías no desaparecerán inmediatamente en una economía planificada, como tampoco el dinero dejará de operar con iguales o muy similares funciones (cuestión que analizamos en Rodríguez Rojo, 2020b). La diferencia estriba en que aquello que se podrá adquirir mediante su uso será lo que la sociedad haya acordado y, hasta donde se pueda, en las cantidades que se haya convenido. De esta manera, la esfera política ganaría peso como mediación necesaria a la hora de organizar la producción, revelándose todos los ciudadanos como interdependientes entre sí para la propia satisfacción de necesidades. Eso que pudiera parecer "paternalismo», pues el individuo pierde centralidad, es en realidad un paso adelante en las conquistas civiles. Para explicar este punto tomaremos un ejemplo, tal vez, algo provocador.

Resulta llamativo que Raventós (2014; Raventós, Torrens y Arcarons, 2014; Raventós y Torrens, 2017), cuando enumera mercancías, no deja pasar la oportunidad de incluir entre ellas la pornografía, a la que considera incluida en «un mercado (casi) libre». Según su razonamiento, resultaría que si un individuo desea adquirir este tipo de bien en el mercado, el resto no podría imponer lo contrario. Estas son, 
insistimos, las coordenadas en que se coloca la discusión. De acuerdo a nuestra propuesta, el resto de ciudadanos tendrían total legitimidad para, a través de mecanismos democráticos y participativos, coartar la creación de ciertos valores de uso. $Y$ aunque, en principio, nada impediría que se generasen este tipo de cosas, al estar sujeta toda la producción-al menos, a la hora de su determinación cualitativa - al control de mecanismos de deliberación pública, podría pasar que la necesidad quedase insatisfecha. Si el conjunto de la sociedad, como resultado de la reflexión colectiva, entiende que no hay necesidad de destinar recursos a generar material audiovisual para consumo onanístico (debido, pongamos por caso, a las consecuencias que tiene sobre la forma en que se percibe a la mujer), no se realizará, independientemente de que alguien esté dispuesto a pagarlo y otra persona a venderlo. Esa es, creemos, una conclusión razonable del principio básico de soberanía popular que se postula desde el republicanismo en conjunción con la tradición socialista.

\section{Conclusiones}

A lo que apuntan las declaraciones de los partidarios de la renta básica universal es al rescate, en gran medida consciente aunque, si se quiere, por la izquierda-, de los principios básicos del liberalismo político. Dibujan un panorama en el que el dinero es la única mediación posible entre el individuo y su reproducción. Frente a ello, hemos aspirado a clarificar cómo la propuesta de la planificación económica porta con más nitidez las potencialidades emancipadoras del proyecto republicano. Un proyecto que, consideramos, debería ir más allá de la redistribución monetaria entre ricos y pobres.

Una república democrática plenamente desarrollada debería caracterizarse por la participación política de toda la ciudadanía en las decisiones que determinan la forma en que se dota de los medios con los que se mantiene y transforma. Marx y Engels llamaron a esta situación, tal vez desafortunadamente, «dictadura del proletariado». Se referían, creemos, nada menos que a esto: un Estado de vocación global compuesto por trabajadores y trabajadoras que llevan a cabo la gestión inmediata de la producción, detentando en común la propiedad sobre el capital social. Al converger en el conjunto de la población las condiciones de ciudadanía y clase obrera, se eliminan las cortapisas que, como las diferencias de clase, hoy afectan a aquellos principios de libertad, igualdad y solidaridad (noción que preferimos a la tradicional «fraternidad», al estar libre de las connotaciones familiares). Aunque no hablamos del final de la historia, no quedaría ya nada que separe a la humanidad de adentrarse en el punto más álgido de la modernidad; y por ende se encuentra notablemente más cerca, ubicada en el entramado de instituciones que pueden alumbrarla, de esa lejana meta a la que llamamos socialismo.

En un documento de estas características no podemos aspirar a clausurar el debate. Ni siquiera a abordarlo en su totalidad. Son muchos los aspectos que lindan con esta discusión, que trascienden ampliamente tanto la planificación como la renta básica: nos enfrentamos de cara nada menos que a la expresión política de la emancipación. Y si hay un asunto que urge y que justifica todo cruce e intercambio de argumentos, es precisamente este. 


\section{Agradecimientos}

A Ramón Soriano, por invitarme a participar en este número y por hacerme avanzar desde la disensión con la lectura de su trabajo. También a Jesús López por las horas de discusión que hemos compartido sobre estos y otros temas.

\section{Bibliografía}

Albarracín, D. (2015). «Hacia un esquema de trabajo libre y solidario en una sociedad emancipada». Laberinto 43: 5-18.

Arcarons, J., Raventós, D. y Torrens, L. (2017). Renta básica incondicional. Una propuesta de financiación racional y justa. Barcelona: El Serval.

Astarita, R. (2018). "Reformismo y marxismo». En Qué enseña la economía marxista. 200 años de Marx, eds. Guerrero, D. y Nieto, M. (pp. 233-62). Madrid: El Viejo Topo.

Arrizabalo, X. (2014). Capitalismo y economía mundial. Madrid: Instituto Marxista de Economía.

Capella, J. R. (1997). Fruta prohibida. Una aproximación histórico-teórica al estudio del derecho y del estado. Madrid: Trotta.

Cockshott, P. y Nieto, M. (2017). Ciber-comunismo. Planificación económica, computadoras y democracia. Madrid: Trotta.

Del Rosal, M. (2019). La gran revelación. De cómo la teoría monetaria moderna pretende salvarnos del capitalismo salvando el capitalismo. Madrid: Ecobook.

Domènech, A. (2013). «La metáfora de la fraternidad republicano-democrática revolucionaria y su legado al socialismo contemporáneo». Revista de Estudios Sociales 46: 14-23.

(2019). El eclipse de la fraternidad. Madrid: Akal.
Hayek, F. A. (1997). La fatal arrogancia. Los errores del socialismo. Madrid: Unión. Husson, M. (2017). «El espejismo del ingreso universal». Viento sur. Disponible en: https://vientosur.info/el-espejismo-delingreso-universal/.

Marx, K. (1999). Manuscritos: economía y filosofía. Madrid: Alianza.

Nieto, M. (2020). «¿Es posible el cálculo económico en el socialismo? Crítica a la nueva lectura austriaca». Revista de Economía Institucional 22 (42): 127-51.

(2015). Cómo funciona la economía capitalista. Una introducción a la teoría del valor-trabajo de Marx. Madrid: Escolar y Mayo.

Peña-Miguel, N. y Peña Esteban, I. (2014) «Hacia una prestación social básica en un Estado del bienestar» Lan Harremanak 31 (2): 16-35.

Rallo, J. R. (2015). Contra la renta básica. Por qué la redistribución de la renta restringe nuestras libertades y nos empobrece a todos. Barcelona: Deusto.

Raventós, D. (2001). La renta básica. Por una ciudadanía más libre, más igualitaria y más fraterna. Barcelona: Ariel.

(2011). «De qué hablamos cuando decimos que la renta básica es (o no) justa. Sobre liberalismos y republicanismos». Revista Internacional de Pensamiento Político 6: 223-40.

(2012). ¿Qué es la renta básica? Preguntas (y respuestas) más frecuentes. Madrid: El Viejo Topo.

(2014). «Pornografía, espermatozoides borbónicos y mercado libre» Público, Disponible en: https://blogs.publico.es/ dominiopublico/11451/pornografia-espermatozoides-borbonicos-y-mercadolibre/

Raventós, D. y Casassas, D. (2003). «La renta básica y el poder de negociación de «los que viven con permiso de otros»». 
Revista Internacional de Sociología 34: 187-201.

Raventós, D., Torrens, L. y Arcarons, J. (2014). «Algunas aclaraciones sobre la financiación de la Renta Básica. Entrevista» Red Renta Básica. Disponible en: http://www.redrentabasica.org/rb/rrbantigua_1192/

Raventós, D. y Torrens, L. (2017). «Empleo, reducción de jornada, fiscalidad, mercados, sindicatos, renta básica», Red Renta Básica. Disponible en: http://www. redrentabasica.org/rb/empleo-reduccionde-jornada-fiscalidad-mercados-rentabasical

Rodríguez Rojo, J. (2019). La revolución en El capital. Significados y potencial de la lucha de clases. Madrid: Garaje.

- (2020a). "Derechos humanos y ciudadanía global en el marco de la producción del capital». En Las fronteras de los derechos humanos. Problemas, discusión y soluciones eds. Soriano, R., Sánchez, D. y Suárez, J. C. (pp.148-68). Madrid: Dykinson.

(2020b). Rodríguez Rojo, J. (2020). «Maquinaria, ordenadores y superación del capital. Una aproximación crítica al ciber-comunismo». Teknokultura. Revista de cultura digital y movimientos sociales, 17(2): 113-120.

Schmitt, C. (2014). El concepto de lo político. Madrid: Alianza.

Shaikh, A. (2016). Capitalism. Competition, Conflict, Crisis. New York: Oxford University Press

Starosta, G. y Caligaris, G. (2017). Trabajo, valor y capital. De la crítica marxiana de la economía política al capitalismo contemporáneo. Buenos Aires: Universidad de Quilmes.

Soriano, R. (2012). Por una renta básica universal. Un mínimo para todos. Córdoba: Almuzara.
Torres, J. (2019). La renta básica. ¿Qué es, cuántos tipos hay, cómo se financia y qué efectos tiene? Barcelona: Deusto. Van Parijs, P. (2001). «A Basic Income for All». En eds.Cohen, J. y Cohen, J.What's Wrong with a Free Lunch? (pp. 3-26). Beacon Press.

Zamora, D. (2017). «The Case Against a Basic Income». Jacobin. Disponible en: https://www.jacobinmag.com/2017/12/ universal-basic-income-inequality-work. 
